\title{
Is age at menarche associated with total mortality? The Tromsø Study
}

This article was published in the following Dove Press journal: International Journal of Women's Health

\section{Marie Wasmuth Lundblad Bjarne K Jacobsen}

Department of Community Medicine, UiT The Arctic University of Norway, Tromsø, Norway
Correspondence: Marie Wasmuth Lundblad

UiT Norges Arktiske Universitet, Postboks 6050 Langnes, 9037 Tromsø, Norway

Tel +47 77644816

Email marie.w.lundblad@uit.no
Purpose: Early age at menarche (AAM) has been associated with increased mortality and morbidity, including premature death from all causes, breast cancer and cardiovascular diseases. The aim of this study was to examine the association between AAM and all-cause mortality.

Subjects and methods: A total of 12,409 women aged 25-94 years who took part in the fourth Tromsø Study in Norway during 1994-1995 were included in this prospective population-based study with a mean 18.7 years of follow-up. Multivariate Cox proportional hazard analysis was used to investigate the association between AAM and all-cause mortality with adjustment for known confounders (age, body mass index, physical activity, level of education and smoking history).

Results: During the 18.7 years of follow-up, a total of 2,203 women died. There was no association between AAM and all-cause mortality before or after adjusting for possible confounding factors.

Conclusion: This prospective study of 12,409 women did not find any association between AAM and all-cause mortality

Keywords: menarche, mortality, population-based, prospective, puberty

\section{Introduction}

Menarche is the first menstrual bleeding and represents the beginning of reproductive life. Average age at menarche (AAM) worldwide is 12 years, but it differs between girls according to ethnicity, living standard and lifestyle. ${ }^{1}$ Menarche normally occurs between the ages of 10 and 15 years, but the variability in normal age of menarche has been discussed. ${ }^{2}$ A major secular trend in AAM has been observed since the 19th century when the mean menarcheal age was approximately 17 years, and the decrease in AAM has been as rapid as 12 months per decade. ${ }^{3,4}$

Previous studies have shown an association between early AAM and earlier all-cause mortality, ${ }^{5}$ cardiovascular mortality, ${ }^{6-9}$ higher risk of breast cancer, ${ }^{10}$ cardiovascular disease (CVD), ${ }^{1,8}$ diabetes, ${ }^{11-16}$ obesity ${ }^{15,17}$ and metabolic syndrome. ${ }^{15,18-21}$ Early AAM has also been associated with psychological disorders, depression, smoking and alcohol use in adolescence and early sexual behavior. ${ }^{22-24}$

A systematic review of the literature found that 1-year increase in AAM was associated with a 3\% lower all-cause mortality (hazard ratio [HR] 0.97, 95\% confidence interval [CI] 0.96-0.98). ${ }^{5}$

The aim of this study was to investigate the association between AAM and allcause mortality among women living in Tromsø, Norway. The hypothesis was that early menarche was associated with increased mortality. 


\section{Subjects and methods Subjects}

Tromsø is the largest city in the north of Norway, with 72,681 inhabitants by January 1, 2015. ${ }^{25,26}$ The Tromsø Study, which is a population-based prospective study, first started in 1974 and is one of the largest epidemiological studies in Norway. ${ }^{26}$

The current analyses are based on the largest of the surveys (Tromsø 4) conducted during 1994-1995 and 27,158 men and women participated. A total of 19,078 women aged 25-94 years were invited to Tromsø 4, of which 14,293 women (75\%) participated. ${ }^{26}$

Women who did not consent to contribute to information for study ( $\mathrm{n}=120)$, women who did not report AAM $(n=1,763)$ and one woman who reported AAM of 33 years were excluded. Thus, 12,409 women were eligible for inclusion in our study.

\section{Included variables}

The main independent variable was AAM in Tromsø 4. In a self-administered questionnaire, the women were asked "How old were you when you started menstruating (age)?" The continuous variable was recorded in the following groups: $<12$ years and $12,13,14,15$ and $>15$ years. Only $1.3 \%$ were 10 years or younger at menarche; this group was considered too small for comparison, and the youngest menarcheal group was therefore coded to $<12$ years. We have previously found high reproducibility of information concerning AAM with a 7-year time span in the current population. ${ }^{27}$

We also collected information about several other variables that may be associated with both AAM and mortality. Some of these variables were measured (eg, weight $[\mathrm{kg}]$, height $[\mathrm{m}]$, blood pressure $[\mathrm{mmHg}]$ and serum blood lipids $[\mathrm{mmol} / \mathrm{L}]$ ), and some were based on self-report (eg, smoking, physical activity $[\mathrm{PA}]$ at leisure, treatment for hypertension, prior CVDs or diabetes). Age at baseline was included as a continuous variable when the relationships between AAM and other risk factors were analyzed (Table 1). Hypertension was defined as mean systolic blood pressure of $>150 \mathrm{mmHg}$ or diastolic blood pressure of $>95 \mathrm{mmHg}$ or that the woman was a current user of blood-pressurelowering drugs. Body mass index (BMI, $\mathrm{kg} / \mathrm{m}^{2}$ ) was grouped into four BMI groups: underweight (BMI $<18.5 \mathrm{~kg} / \mathrm{m}^{2}$ ), normal weight (BMI 18.5-24.9 kg/m²), overweight (BMI $25-29.9 \mathrm{~kg} / \mathrm{m}^{2}$ ) and obesity (BMI $\left.\geq 30.0 \mathrm{~kg} / \mathrm{m}^{2}\right)$. Cigarette smoking was classified as never, previously or current cigarette smoking. PA (hours/week) was grouped into sedate (light PA $<1$ hour/week), moderate (hard PA $<1$ hour/week or light $\mathrm{PA} \geq 1$ hour/week) or active (hard PA $\geq 1$ hour/ week). For some variables, there were some missing values, but these accounted for a small percentage of the total dataset and were not expected to influence the end result.

The following variables were, based on previous studies, considered to be possible confounders (and not mediators) of the relationship between AAM and total mortality: age, smoking, PA at leisure, BMI and level of education.

\section{Follow-up and statistical analyses}

Follow-up started with the date the participant attended the examination in Tromsø 4 in 1994-1995 and lasted until June 30, 2015, date of emigration or date of death, whichever came first. The unique 11-digit personal identification number assigned to all Norwegian residents was used for linkage between the study population and the Norwegian Cause of Death Registry and information regarding emigration held by Statistics Norway. The Cause of Death Registry covers data on all persons with residence in the country, independent of where they died. Mean duration of follow-up was 18.7 years. During this time, 2,203 women died and 140 emigrated.

The statistical analyses included cross-tabulations, linear regression (for continuous variables), binary logistic regression (for categorical variables) and Cox proportional hazard regression.

In the descriptive analyses of associations between AAM and possible confounders (Table 1), age at baseline was included as a covariate in the model to provide age-adjusted $p$-values for linear trend. When assessing the relationship between AAM and total mortality (Table 2), we applied Cox proportional hazard regression with attained age as the time variable.

In the Cox proportional hazard regression analyses, the reference categories were 13 years for AAM, less than university level of education, normal BMI, sedate activity level and never smokers.

Separate survival analyses were performed for women with attained age of 69 years or below and older women to examine whether there were differences in the relationship between AAM with increasing age. We ran similar stratified analyses for current, former and never smokers.

HR was interpreted as risk. 95\% CIs were given. A twosided $p$-value of $<0.05$ was considered statistically significant. We used IBM Statistical Package for the Social Sciences (SPSS; IBM Corporation, Armonk, NY, USA) statistics 22 and SAS 9.4 software (SAS Institute Inc., Cary, NC, USA) to analyze the data. 
Table I Relationships between AAM and demographic and lifestyle variables

\begin{tabular}{|c|c|c|c|c|c|c|c|c|}
\hline \multirow[t]{2}{*}{ Variables } & \multicolumn{8}{|l|}{ AAM (years) } \\
\hline & $<\mathbf{1 2}$ & 12 & 13 & 14 & 15 & $>15$ & $\begin{array}{l}P \text {-value } \\
\text { for linear } \\
\text { trend }\end{array}$ & $\begin{array}{l}\text { p-value for } \\
\text { linear trend } \\
\text { (age adjusted) }\end{array}$ \\
\hline Subjects (n) & $9.0(1,120)$ & $19.6(2,428)$ & $27.6(3,429)$ & $24.9(3,092)$ & $13.3(1,646)$ & $5.6(694)$ & & \\
\hline Age (years) & $41.84(12.12)$ & $43.49(13.66)$ & $45.22(14.58)$ & $48.36(15.56)$ & $50.68(16.02)$ & $52.81(16.83)$ & $<0.001$ & \\
\hline$\%$ with hypertension & $14.7(165)$ & $15.9(385)$ & $\mid 8.5(63 \mid)$ & $21.9(677)$ & $25.5(419)$ & $30.8(2 \mid 3)$ & $<0.001$ & 0.006 \\
\hline BMI $\left(\mathrm{kg} / \mathrm{m}^{2}\right)$ & $25.81(4.64)$ & $25.13(4.33)$ & $24.67(4.14)$ & $24.47(4.07)$ & $24.40(3.97)$ & $24.24(4.10)$ & $<0.001$ & $<0.001$ \\
\hline \multicolumn{9}{|l|}{ BMI } \\
\hline Underweight & $0.8(9)$ & $1.4(33)$ & $1.8(62)$ & $2.4(75)$ & $2.1(34)$ & $4.2(29)$ & $<0.001$ & $<0.001$ \\
\hline Normal weight & $49.2(549)$ & $55.2(1,339)$ & $58.8(2,009)$ & $59.8(1,848)$ & $59.6(98 I)$ & $58.9(408)$ & & \\
\hline Overweight & $33.9(378)$ & $30.6(742)$ & $28.5(975)$ & $27.7(855)$ & $29.2(480)$ & $27.4(190)$ & & \\
\hline Obesity & 16.I (180) & $12.8(309)$ & $10.9(37 I)$ & $10.1(311)$ & $9.1(150)$ & $9.5(66)$ & & \\
\hline Total cholesterol (mmol/L) & $5.81(1.32)$ & $5.94(1.34)$ & $5.93(1.36)$ & $6.12(1.40)$ & $6.23(1.40)$ & $6.29(1.48)$ & $<0.001$ & 0.052 \\
\hline Triglycerides (mmol/L) & $1.33(0.83)$ & $1.33(0.85)$ & $1.29(0.83)$ & $1.35(0.85)$ & $1.35(0.87)$ & $\mathrm{I} .44(1.01)$ & 0.004 & 0.001 \\
\hline $\mathrm{HDL}(\mathrm{mmol} / \mathrm{L})$ & $1.60(0.39)$ & $1.62(0.40)$ & $1.64(0.40)$ & $1.66(0.4 I)$ & $1.67(0.4 \mathrm{I})$ & $1.65(0.42)$ & $<0.001$ & $<0.001$ \\
\hline Alcohol (times/month) & $2.09(2.76)$ & $2.12(2.99)$ & $2.12(3.05)$ & $2.12(3.23)$ & $1.96(2.92)$ & $1.83(3.32)$ & 0.042 & 0.62 \\
\hline \multicolumn{9}{|l|}{ Smoking } \\
\hline Never & 39.7 (432) & $39.3(924)$ & $4 I . I(I, 376)$ & $40.4(1,226)$ & $42.4(687)$ & $40.9(274)$ & 0.008 & 0.67 \\
\hline Previously & $21.9(238)$ & $22.2(52 I)$ & $22.6(758)$ & $23.3(708)$ & $24.3(394)$ & $24.5(164)$ & & \\
\hline Currently & $38.5(419)$ & $38.5(904)$ & $36.3(1,215)$ & $36.3(1,10 I)$ & $33.3(539)$ & $34.6(232)$ & & \\
\hline$\%$ with nulliparity & $17.2(189)$ & $16.4(391)$ & $16.7(560)$ & $15.5(473)$ & $14.4(232)$ & $13.0(88)$ & 0.003 & 0.10 \\
\hline Parity & $1.90(1.31)$ & $1.96(1.33)$ & $1.97(1.4 I)$ & $2.12(1.5 \mathrm{I})$ & $2.21(1.54)$ & $2.31(1.63)$ & $<0.001$ & 0.26 \\
\hline \multicolumn{9}{|l|}{ PA } \\
\hline Sedate & I7.I (190) & $17.7(425)$ & $18.7(633)$ & 19.5 (598) & $21.2(344)$ & $25.0(173)$ & $<0.001$ & 0.64 \\
\hline Moderate & $53.2(591)$ & $56.5(1,357)$ & $55.3(1,878)$ & $56.0(1,7 \mid 8)$ & $57.5(935)$ & $55.4(383)$ & & \\
\hline Active & $29.6(329)$ & $25.8(619)$ & $26.0(882)$ & $24.5(75 I)$ & $21.3(346)$ & $19.5(135)$ & & \\
\hline Subjects with MI & $0.8(9)$ & $0.9(2 \mathrm{I})$ & I.3 (43) & $1.9(58)$ & I.8 (29) & $2.2(15)$ & $<0.001$ & 0.57 \\
\hline Subjects with AP & $1.6(18)$ & $2.0(49)$ & $3.2(110)$ & $4.0(123)$ & $4.6(75)$ & $5.6(39)$ & $<0.001$ & 0.54 \\
\hline Subjects with stroke & $0.5(6)$ & $0.8(19)$ & $1.2(40)$ & I.5 (45) & $1.4(23)$ & $1.9(13)$ & 0.001 & 0.69 \\
\hline Subjects with diabetes & $1.3(14)$ & $1.5(36)$ & $1.5(52)$ & $2.0(62)$ & $1.9(32)$ & $2.6(18)$ & 0.008 & 0.29 \\
\hline $\begin{array}{l}\text { Subjects with heart attack } \\
\text { or AP in close family }\end{array}$ & $50.0(527)$ & $48.3(1, I 13)$ & $46.6(I, 5 \mid 2)$ & $48.6(I, 4 \mid I)$ & 48.0 (739) & $49.0(317)$ & 0.82 & $<0.001$ \\
\hline $\begin{array}{l}\text { Subjects with university } \\
\text { education }\end{array}$ & $37.4(420)$ & $32.2(782)$ & $31.8(1,092)$ & $26.5(819)$ & $23.3(383)$ & $20.2(140)$ & $<0.001$ & $<0.001$ \\
\hline
\end{tabular}

Note: Values are presented as percentage (number) or mean (SD).

Abbreviations: AAM, age at menarche; AP, angina pectoris; BMI, body mass index; HDL, high-density lipoprotein; MI, myocardial infarction; PA, physical activity.

\section{Ethics and permission}

Approval was given from the Data and Publication committee of the Tromsø Study and access to a data file with the described variables was received. The Tromsø Study is approved by the Regional Committee for Medical Research Ethics (REK) and the investigation is covered by this approval. All included subjects provided informed written consent.

Table 2 Relationships between AAM and all-cause mortality

\begin{tabular}{|c|c|c|c|c|c|c|c|}
\hline AAM (years) & $\begin{array}{l}\text { Number of } \\
\text { women (\%) }\end{array}$ & $\begin{array}{l}\text { Number } \\
\text { of deaths }\end{array}$ & Person-years & $\mathrm{HR}^{*}$ & $95 \% \mathrm{Cl}$ & $\mathbf{H R} * *$ & $95 \% \mathrm{Cl}$ \\
\hline$<12$ & $\mathrm{I}, \mathrm{I} 20(9.0)$ & 112 & 21,849 & 1.06 & $0.87-|.3|$ & 1.05 & $0.85-1.29$ \\
\hline 12 & $2,428(19.6)$ & 302 & 46,702 & 0.99 & $0.86-1.14$ & 0.96 & $0.83-1.11$ \\
\hline 13 & $3,429(27.6)$ & 515 & 65,075 & 1 & & 1 & \\
\hline 14 & $3,092(24.9)$ & 656 & 57,060 & 1.05 & $0.93-1.18$ & 1.02 & $0.91-1.15$ \\
\hline 15 & $\mathrm{I}, 646(13.3)$ & 410 & 29,682 & 1.00 & $0.87-1.13$ & 0.99 & $0.86-1.12$ \\
\hline$>15$ & $694(5.6)$ & 208 & $|2,20|$ & 1.09 & $0.93-1.29$ & 1.05 & $0.89-1.23$ \\
\hline$p$-value for linear trend & & & & 0.57 & & 0.73 & \\
\hline
\end{tabular}

Notes: *HR, adjusted for attained age only. ${ }^{*}$ HR, adjusted for the attained age, BMI, PA, level of education, smoking.

Abbreviations: AAM, age at menarche; BMI, body mass index; $\mathrm{Cl}$, confidence interval; HR, hazard ratio; PA, physical activity. 


\section{Results}

\section{Associations between AAM and demographic and lifestyle variables}

Our study included 12,409 women. Mean age at the start of follow-up was 46.5 years.

The range of AAM according to the self-administered questionnaire was 8-21 years. Most females were 13 or 14 years ( $27.6 \%$ and $24.9 \%$, respectively) at menarche.

There was a strong, statistically significant positive relationship between AAM and age at baseline $(p<0.001)$. Women who were $<12$ years old at menarche were 11 years younger than women who were $>15$ years old (Table 1). Table 1 displays the unadjusted relationships between AAM and some potential confounding variables. We also gave the $p$-value for linear relationships both before and after adjustments for age. It is noted that adjustment for age had a strong impact on some of the relationships (eg, that for hypertension).

After age adjustment, AAM was significantly inversely associated with BMI, educational level, serum total cholesterol, serum triglycerides and hypertension. The relationship with serum total cholesterol was of borderline significance, however. Age-adjusted serum high-density lipoprotein (HDL) cholesterol was positively associated with AAM (Table 1). Alcohol consumption, smoking, parity and PA were not significantly associated with AAM after adjusting for age.

AAM and the prevalence of diagnosed CVDs (previous heart attack, angina pectoris or stroke) were not significantly associated after adjusting for age, but the probability of having a family member with CVD was lower in women with high AAM (Table 1).

\section{Associations between AAM and total mortality}

During the follow-up (mean 18.7 years), 2,203 women died.

There was no significant association between AAM and all-cause mortality before or after adjusting for possible confounding factors (Table 2). There was an indication of a U-shaped relationship between AAM and all-cause mortality, but the presence of a nonlinear trend was not supported by including a second-order term in the model.

When stratified for smoking habits (current smoking, previous smoking, never daily smoking), no association was found between AAM and total mortality in any of the three strata. In women with attained age of $<70$ years (including 453 deaths), we found some indications of a direct, positive relationship between AAM and total mortality ( $p$-value for linear trend over the AAM categories $=0.05$ ), whereas no relationship was found in women with attained age of 70 years and older (1,750 deaths, $p$-value for linear trend over the AAM categories $=0.7$ ).

\section{Discussion}

This prospective, population-based study found no overall association between AAM and all-cause mortality before or after adjusting for confounding factors.

Most previous studies found a significant inverse relationship between AAM and all-cause mortality.,11 The review by Charalampopoulos et $\mathrm{al},{ }^{5}$ which included nine studies that investigated the relationship between AAM and allcause mortality, cardiovascular mortality, stroke and death from IHD, found an inverse association between AAM and death from all-causes. Two of the included studies showed a U-shaped association. Another study observed a U-shaped (or an inverted J-shaped) association between AAM and all-cause mortality with a higher all-cause mortality among those with high AAM (18 or 19 years) and among those with low AAM $\left(<14\right.$ years) compared to AAM of 14 years. ${ }^{28}$ In addition, the results of the current study may give hints of a, albeit statistically not significant, nonlinear relationship.

Similar to some previous studies, ${ }^{8}$ we found that there were relationships between AAM and some known risk factors for, inter alia, CVDs (Table 1). There was a consistent finding of inverse age-adjusted relationships between AAM and BMI, serum total cholesterol and triglycerides, low HDL cholesterol, hypertension and a family history of CVDs. Despite these relationships, we do not find an association between AAM and all-cause mortality.

Some studies have found a link between early AAM and higher occurrence of risk-taking behavior such as early sexual intercourse and more unprotected sex, early alcohol drinking and smoking. ${ }^{22,23}$ Such behavior could be attributed to the experiences of early maturation, and the feeling of entering adulthood could be strengthened by exploring what one considers as adult behavior. After adjusting for age, we found no association between AAM and smoking or alcohol consumption, however.

Some have suggested that women with late AAM, alone or in combination with a high menopausal age, could have lower mortality because they are biologically younger than their actual age..$^{28}$ If the latter hypothesis was true, we expected increasing AAM to be associated with lower all-cause mortality, but we found no consistent association. 
We have no obvious explanation to why our result contrasts with results from other studies.

\section{Limitations}

This study has some limitations. We have no information regarding weight, height or PA level before menarche occurred. Although there is a strong tracking between childhood and adolescent BMI and BMI in adulthood, ${ }^{29-31}$ these are important predictors for both AAM and mortality and should be taken into consideration. Other factors that could affect AAM are both excessive training and anorexia nervosa, which delay menarche ${ }^{32}$ and increase mortality. Potentially, there could be information bias due to the selfreport of behavioral factors such as smoking and alcohol consumption.

It is difficult to completely control for this potential bias other than by carrying out a prospective follow-up from pre-menarcheal childhood to adulthood to secure that the information regarding AAM and, for example, BMI in adolescence is valid. We have found a high reproducibility of self-reported AAM with a 7-year time span in the current population. If anything, the reproducibility was higher in older than in relatively young women. ${ }^{27}$ However, a high reproducibility does not equal validity, and it is difficult to know whether the self-reported AAM is the correct AAM. Thus, recall bias could be present also in our study. However, several studies have investigated the validity of self-reported $\mathrm{AAM}$ and have found relatively high correlations between self-reported AAM and the correct AAM $(r=0.52-0.83)$, and that the mean recalled AAM does not differ significantly from the correct AAM, and concluded that self-reported AAM is accurate enough to be used in epidemiological studies. ${ }^{33-37}$ Furthermore, to explain the lack of an inverse relationship between AAM and total mortality in our study by recall bias, we have to assume that, for example, older women (with higher mortality) have systematically reported a higher AAM than the correct AAM. Although we cannot completely rule this out, we do not find it likely.

\section{Strengths}

This study has several strengths. It includes a large study sample of 12,409 women. The response rate in the Tromsø Study (Tromsø 4) is high, and after excluding those who did not report AAM, $65 \%$ of all women aged 25 years and older in the entire Tromsø municipality were included in our analyses. Living conditions in Tromsø are similar to those of other high-income countries, and there is reason to believe that the included women are representative for the general female population in Norway and probably other high-income countries, and that our results have external validity. Another strength is that physical examinations were performed by trained health care professionals. In addition, the participants were provided with guidance when answering the questionnaire and the risk of misunderstanding questions or wrongfully reporting from the physical examination is minimal.

\section{Conclusion}

We find no significant association between menarcheal age and all-cause mortality in the population in Tromsø. This result is contradictory to most previous findings, including our own, ${ }^{7,28}$ but we are currently not able to pinpoint the reasons for this difference in findings. Adjustments for known possible confounders cannot explain our findings.

\section{Ethics approval and informed consent}

The Tromsø Study was approved by the Data Inspectorate of Norway and the Regional Committee of Medical and Health Research Ethics, North Norway (Reference: 2009/2536/ REK nord). Informed written consent was obtained from all individual participants included in the analyses.

\section{Data availability}

No data available. The results presented are based on analyses of the much larger Tromsø Study database, and each project must be authorized and data cannot be shared.

\section{Acknowledgments}

This particular research project did not receive any specific funding. The Tromsø Study as a cohort has since 1974 been supported by a number of institutions and funding agencies, mostly the University of Tromsø, now UiT The Arctic University of Norway, but also the Northern Norway Regional Health Authority Medical Program, and supported by grants from the Norwegian Research Council, among others. The administration of the questionnaires with questions about AAM was conducted by the National Health Screening Services, Oslo, Norway. No funding body had any role in the design of the study and collection, analysis and interpretation of data and in writing the manuscript.

\section{Author contributions}

MWL conducted most of the statistical analyses and drafted the manuscript. BKJ suggested the topic for research, conducted some of the analyses, and contributed to the study's 
analytical strategy. Both authors took part in the revision of the drafted manuscript for intellectual content, have read and approved the final manuscript, and agree to be accountable for all aspects of the work.

\section{Disclosure}

The authors report no conflicts of interest in this work.

\section{References}

1. Qiu C, Chen H, Wen J, et al. Associations between age at menarche and menopause with cardiovascular disease, diabetes, and osteoporosis in Chinese women. J Clin Endocrinol Metab. 2013;98(4):1612-1621.

2. Hillard PJA. Menstruation in adolescents: what's normal? Medscape J Med. 2008;10(12):295.

3. Kaplowitz P. Pubertal development in girls: secular trends. Curr Opin Obstet Gynecol. 2006;18(5):487-491.

4. Ong KK, Ahmed ML, Dunger DB. Lessons from large population studies on timing and tempo of puberty (secular trends and relation to body size): the European trend. Mol Cell Endocrinol. 2006;254-255:8-12.

5. Charalampopoulos D, McLoughlin A, Elks CE, Ong KK. Age at menarche and risks of all-cause and cardiovascular death: a systematic review and meta-analysis. Am J Epidemiol. 2014;180(1):29-40.

6. Canoy D, Beral V, Balkwill A, et al; Million Women Study Collaborators. Age at menarche and risks of coronary heart and other vascular diseases in a large UK cohort. Circulation. 2015;131(3):237-244.

7. Jacobsen BK, Oda K, Knutsen SF, Fraser GE. Age at menarche, total mortality and mortality from ischaemic heart disease and stroke: the Adventist Health Study, 1976-88. Int J Epidemiol. 2009;38(1):245-252.

8. Lakshman R, Forouhi NG, Sharp SJ, et al. Early age at menarche associated with cardiovascular disease and mortality. J Clin Endocrinol Metab. 2009;94(12):4953-4960.

9. Murakami K, Metoki H, Satoh M, et al. Menstrual factors and stroke incidence in Japanese postmenopausal women: the Ohasama study. Neuroepidemiology. 2016;47(2):109-116.

10. Collaborative Group on Hormonal Factors in Breast Cancer. Menarche, menopause, and breast cancer risk: individual participant meta-analysis, including 118964 women with breast cancer from 117 epidemiological studies. Lancet Oncol. 2012;13(11):1141-1151.

11. Wu X, Cai H, Kallianpur A, et al. Age at menarche and natural menopause and number of reproductive years in association with mortality: results from a median follow-up of 11.2 years among 31,955 naturally menopausal Chinese women. PLoS One. 2014;9(8):e103673.

12. Mueller NT, Duncan BB, Barreto SM, et al. Earlier age at menarche is associated with higher diabetes risk and cardiometabolic disease risk factors in Brazilian adults: Brazilian Longitudinal Study of Adult Health (ELSA-Brasil). Cardiovasc Diabetol. 2014;13(1):22.

13. Stöckl D, Döring A, Peters A, et al. Age at menarche is associated with prediabetes and diabetes in women (aged 32-81 years) from the general population: the KORA F4 study. Diabetologia. 2012;55(3):681-688.

14. Day FR, Elks CE, Murray A, Ong KK, Perry JR. Puberty timing associated with diabetes, cardiovascular disease and also diverse health outcomes in men and women: the UK Biobank study. Sci Rep. 2015; $5: 11208$

15. Won JC, Hong JW, Noh JH, Kim D-J. Association between age at menarche and risk factors for cardiovascular diseases in Korean women: the 2010 to 2013 Korea national health and nutrition examination survey. Medicine. 2016;95(18):e3580.

16. Yang L, Li L, Peters SA, et al. Age at menarche and incidence of diabetes: a prospective study of 300,000 women in China. Am J Epidemiol. 2017; 187(2):190-198.
17. Prentice P, Viner R. Pubertal timing and adult obesity and cardiometabolic risk in women and men: a systematic review and meta-analysis. Int J Obes (Lond). 2013;37(8):1036-1043.

18. Kivimaki M, Lawlor DA, Smith GD, et al. Association of age at menarche with cardiovascular risk factors, vascular structure, and function in adulthood: the cardiovascular risk in young Finns study. Am J Clin Nutr. 2008;87(6):1876-1882.

19. Stöckl D, Meisinger C, Peters A, et al. Age at menarche and its association with the metabolic syndrome and its components: results from the KORA F4 study. PLoS One. 2011;6(10):e26076.

20. Lim SW, Ahn JH, Lee JA, Kim DH, Seo J-H, Lim JS. Early menarche is associated with metabolic syndrome and insulin resistance in premenopausal Korean women. Eur J Pediatr. 2016;175(1):97-104.

21. Cho YJ, Lee GH. Association of age at menarche with metabolic syndrome and components of metabolic syndrome in premenopausal women, Korea national health and nutrition examination survey VI. Int J Diabetes Dev Ctries. 2016;36(3):345-351.

22. Downing J, Bellis MA. Early pubertal onset and its relationship with sexual risk taking, substance use and anti-social behaviour: a preliminary cross-sectional study. BMC Public Health. 2009;9(1):446.

23. Gaudineau A, Ehlinger V, Vayssiere C, Jouret B, Arnaud C, Godeau E. Factors associated with early menarche: results from the French Health Behaviour in School-aged Children (HBSC) study. BMC Public Health. 2010;10(1):1-7.

24. Stice E, Presnell K, Bearman SK. Relation of early menarche to depression, eating disorders, substance abuse, and comorbid psychopathology among adolescent girls. Dev Psychol. 2001;37(5):608.

25. Statistics Norway [webpage on the Internet]. Population. 2015. Available from: http://www.ssb.no/befolkning/statistikker/folkemengde/ aar/2015-02-19. Accessed September 4, 2015.

26. Jacobsen BK, Eggen AE, Mathiesen EB, Wilsgaard T, Njølstad I. Cohort profile: the Tromsø Study. Int J Epidemiol. 2011;41(4):961-967.

27. Lundblad MW, Jacobsen BK. The reproducibility of self-reported age at menarche: the Tromsø Study. BMC Womens Health. 2017;17(1):62.

28. Jacobsen B, Heuch I, Kvåle G. Association of low age at menarche with increased all-cause mortality: a 37-year follow-up of 61,319 Norwegian women. Am J Epidemiol. 2007;166(12):1431-1437.

29. Evensen E, Emaus N, Kokkvoll A, Wilsgaard T, Furberg A-S, Skeie G. The relation between birthweight, childhood body mass index, and overweight and obesity in late adolescence: a longitudinal cohort study from Norway, the Tromsø Study, fit futures. BMJ Open. 2017;7(6): e015576.

30. Serdula MK, Ivery D, Coates RJ, Freedman DS, Williamson DF, Byers T. Do obese children become obese adults? A review of the literature. Prev Med. 1993;22(2):167-177.

31. Simmonds M, Llewellyn A, Owen C, Woolacott N. Predicting adult obesity from childhood obesity: a systematic review and meta-analysis. Obes Rev. 2016;17(2):95-107.

32. Yermachenko A, Dvornyk V. Nongenetic determinants of age at menarche: a systematic review. Biomed Res Int. 2014;2014:371583.

33. Koprowski C, Coates RJ, Bernstein L. Ability of young women to recall past body size and age at menarche. Obes Res. 2001;9(8):478-485.

34. Must A, Phillips SM, Naumova EN, et al. Recall of early menstrual history and menarcheal body size: after 30 years, how well do women remember? Am J Epidemiol. 2002;155(7):672-679.

35. Cairns BJ, Liu B, Clennell S, et al. Lifetime body size and reproductive factors: comparisons of data recorded prospectively with self reports in middle age. BMC Med Res Methodol. 2011;11(1):7.

36. Cooper R, Blell M, Hardy R, et al. Validity of age at menarche selfreported in adulthood. J Epidemiol Community Health. 2006;60(11): 993-997.

37. Damon A, Bajema C. Age at menarche: accuracy of recall after thirtynine years. Hum Biol. 1974;46(3):381. 
International Journal of Women's Health

Dovepress

\section{Publish your work in this journal}

The International Journal of Women's Health is an international, peerreviewed open-access journal publishing original research, reports, editorials, reviews and commentaries on all aspects of women's healthcare including gynecology, obstetrics, and breast cancer. The manuscript management system is completely online and includes Visit http://www.dovepress.com/testimonials.php to read real quotes from published authors.

Submit your manuscript here: http://www.dovepress.com/international-journal-of-womens-health-journal 